ESTUDOS LINGÜIÍSTICOS 


\title{
ENSINO DE PORTUGUÊS - SEGUNDA LÍNGUA
}

\author{
Basílio Agostini * \\ Odete Pereira da Silva Menon*
}

oi firmado recentemente um convênio de cooperação políticoeconômica congregando os quatro países do extremo-sul da América do Sul, o chamado MERCosul (Argentina, Brasil, Paraguai, Uruguai). Um dos protocolos decorrentes desse acordo diz respeito ao ensino de português e de espanhol como língua estrangeira nos respectivos países.

Como em outros tantos acordos, estabeleceu-se uma prioridade sem haver mão-de-obra suficiente e adequadamente capacitada para executá-la. Um bom exemplo dessa situação de impasse é o que aconteceu na província do Chaco, Argentina, onde os professores de francês ${ }^{1}$ da rede pública vão ter que passar por uma complementação de estudos, a fim de poderem lecionar português, visto que o francês, como disciplina de língua estrangeira, foi substituído pelo português nos currículos escolares.

Se, por um lado, a implantação de português como língua estrangeira é altamente interessante, pois abre novos mercados de trabalho para os egressos dos cursos de Letras; por outro, põe à mostra a total precariedade de formação específica nessa área. De fato, até onde pudemos verificar, no Brasil não existem

* Universidade Federal do Paraná

1 Comunicação pessoal de um professor nesta situação. 
cursos de graduação que ofereçam habilitação específica no ensino de português como segunda língua.

A situação criada pelo MERCOSUl está a exigir essa formação direcionada. Para dar conta da demanda criada, há que se questionar inicialmente sobre o tipo de docente que se quer ou que se precisa habilitar.

No entanto, na formação de um professor deve-se levar em conta quais dominios de língua serão solicitados no ensino. A preparação do professor será diversa segundo se vise ao domínio ativo ou ao domínio passivo da língua. No domínio pasivo o que está em jogo é acompreensāo. Nesta, a língua vai ser trabalhada como mero instrumental, principalmente voltado ao entendimento de tex tos escritos. A língua escrita, portanto, deverá estar em primeiro plano e a leitura de textos escritos vai constituir a atividade básica do "ensino" da língua. Já para odomínio ativo, o leque de exigências se torna muito mais amplo, na medida em que, além do domínio passivo da língua, isto é, acompreensão, vai ser necessário o desenvolvimento daprodução na língua-alvo, quer na forma oral, quer na forma escrita.

A formação do professor habilitado a desenvolver um ou outro domínio de lingua deverá necessariamente privilegiar aspectos diferentes do conhecimento. De naturezas diferentes também serāo os cursos destinados a habilitar esses docentes.

O que fica evidenciado pelas próprias características do MERCosul é que vai ser exigida uma competência de produção e não somente de recepção. Como consequeência, a formação do professor vai ser bastante complexa, pois vai exigir também uma formação específica na área mais ligada a comércio exterior e um treinamento em correspondência comercial e oficial de naturezas bem diversas.

Além das questōes inerentes à produção e à compreensão de textos escritos, aparece o problema da língua oral, já que o intercâmbio não se limitará à troca de correspondências. Surge então a questão de qual pronúncia adotar no ensino de portugues. Sendo o Brasil um país de extensão territorial considerável, registra-se uma diversidade lingũística ainda não estudada em profundidade. Não se dispõe de descrições de todas as variedades do português do Brasil (doravante $\mathrm{PB}$ ) e a problemática de uma pronúncia padrão se coloca no cerne da questão.

Todavia, para os estados do sul do Brasil, além de São Paulo e Mato Grosso do Sul, geograficamente mais próximos dos outros países do MERCOSUL, esse problema pode ser contornado, se levarmos em consideração que, aí, os diversos dialetos apresentam um bom número de características comuns. Há uma certa norma regional geral comum, no sentido que lhe atribui Coseriu (1979, p.72-85), a qual se sobrepöe às diferenças regionais, sobretudo no que 
diz respeito à norma padrão. Por isso é que um curso de português deve, forçosamente, abordar a questão da variação lingüística existente no $\mathrm{PB}$ e o professor deverá ser treinado a reconhecer os juízos de valor que pesam sobre as diversas pronúncias.

Por outro lado, essa questão da variação também se coloca no sentido inverso do processo, isto é, os diversos países de fala espanhola apresentam diferentes pronúncias e esse fato pode se refletir numa maior ou menor dificuldade de aprendizado dos sons do português. Isso equivale a dizer que vai haver, qualquer que seja a metodologia a ser adotada, uma necessidade de adequação local.

No que concerne à formação de professores de português nos países de fala espanhola, era de se esperar que o ensino de português e, conseqũentemente, a capacitação de docentes nesses países já constituísse uma tradição. $O$ Brasil recebe, desde 1941, alunos, chamados estudantes-convênio, oriundos dos mais diversos paises da América Latina, para freqüentarem cursos universitários, de graduação e pós-graduação, na mais diversas áreas do saber. Parece, em função das discussões realizadas no. Seminário Educação Sem Fronteiras, no final de 1993, em Foz do Iguaçu, que essa situação ideal, de já possuir profissionais habilitados em número suficiente, não chegou a se consolidar nos CEBs (Centros de Estudos Brasileiros) dos países do MERCosul.

Comprovou-se, inclusive com levantamentos realizados pelo Programa do Estudante-Convênio (PEC) no fim dos anos $80^{2}$, que estudantes-convênio desses países, com raras exceções, chegam ao Brasil com um domínio bastante precário do português. Como do ponto de vista da comunicação oral diária o falante de espanhol não tem maiores dificuldades de ser compreendido pelos brasileiros, os estudantes-convênio não se preocupam muito com o aprendizado de português. No entanto, no momento em que eles têm que apresentar os primeiros trabalhos escritos e realizar as primeiras provas, essa não-proficiência se revela catastrófica. Nessa situação, o mito da facilidade de comunicação se desfaz e eles sofrem os primeiros reveses que, muitas vezes, não são superados, com os conseqüentes prejuízos à sua formação escolar, inclusive, ao desligamento do programa. Em geral, no primeiro semestre ou ano de estudos eles acabam sendo reprovados na maior parte das disciplinas, por não serem capazes de produzir textos em português padrão, seja na forma oral seja na escrita, pois a escola exige o domínio desse registro de língua.

O PEC exige do candidato a uma vaga em universidade brasileira que ele apresente uma grau de proficiência em língua portuguesa a ser testado em

2 A profa. Odete Menon participou, na condição de Coordenadora do PEC na UFPR de 1986 a 1988, desses estudos feitos pelo MEC e pelo MRE, gestores do programa. 
prova feita pelos consulados do Brasil. Em princípio, nos países onde funcionam os CEBs, há a oferta de curso de português para os candidatos. Poderia se indagar, então, como se dá o ensino de português nas regiões onde não existem CEBs.

Em vários países sul-americanos existem cursós de licenciatura em português, como por exemplo, em Rosário, Argentina, onde funciona o "Profesorado de Portugués", na Facultad de Humanidades y Artes. Contudo, há problemas relativos à obtenção de material didático e bibliográfico adequado à nova demanda gerada pelo MERCOSUL, o que inclusive motivou a referida faculdade a entrar em contato com instituições brasileiras com vistas ao estabelecimento de intercâmbios de docentes e alunos.

E no Brasil, qual á a situação? ${ }^{3}$ Sabe-se que aqui, como aliás em Portugal, o português não tem uma tradição de ensino como segunda língua, a não ser em raros casos de ofertas, muitas vezes pontuais e únicas, de cursos de português para os estudantes-convênio ou para estrangeiros em geral. ${ }^{4}$

O portugues, assim como o espanhol ${ }^{5}$, jamais conheceu um período de grande agitação de pesquisa motivada por necessidades externas ao seu ensino como língua materna, pois até muito recentemente, não tinha quase projeção no cenário mundial como língua estrangeira. Questiona-se, então, como instituir cursos de formação de professores de português como segunda língua se não há material humano e pedagógico desenvolvidos para tal fim, fato evidenciado inclusive nas conclusões a que se chegou no Seminário mencionado acima. Tal constatação ocorre sempre que é necessário atender a uma clientela com cursos de português como língua estrangeira.

Como criar então uma licenciatura específica sem se dispor desses recursos? A criação de licenciatura deve, ou pelo menos, deveria, ser antecedida de formação de massa crítica, que deve desenvolver projetos de tese ou pesquisa dentro dessa área, abrindo inclusive possibilidades de diversificação nas opçōes de escolha de assuntos para dissertações e teses dos cursos de mestrado e

3 Como uma forma de valorização das respectivas linguas e integração dos falantes das quatro linguas romànticas da Comunidade Econômica Européia (espanhol, francês, italiano e português), está sendo desenvolvido o projeto EUROM 4, cujo objetivo é o ensino de três línguas românticas, simultaneamente, aos alunos da Espanha, França, Itália e de Portugal. Assim, os alunos desses países teriam como linguas estrangeiras as outras trís línguas românicas, mas aprendidas ao mesmo tempo e com a mesma metodologia. O projeto é deservolvido em conjunto pelos quatro países mas com coordenação local de uma universidade participante. (cf. BENVENISTE, 1993)

4 Algumas dessas experiências foram relatadas em comunicaçöes apresentadas no Seminário Educação sem Fronteiras e publicadas nos Anais (1993).

5 Apesar de o espanhol ja ser uma língua internacional há mais tempo que o português. não parece que tenha havido um incremento nas pesquisas de descriçāo da língua, isto É, descriçõestinas da estnutura lingüistica. 
doutorado, para se evitar uma vulgarização quantitativa de cursos tão perigosa como ineficaz.

Acreditamos que já se começa a produzir estudos específicos voltados para as dificuldades lingüisticas existentes devido às semelhanças entre as duas línguas, como demonstram alguns dos artigos que compõem Almeida e Lombello (1989).

O português deverá, espera-se, beneficiar-se das pesquisas que normalmente acompanham os problemas de ensino de uma língua a estrangeiros. Tal ocorreu com o francês e o inglês nas décadas de 60 e 70, com grandes projetos, como o "Français Fondamental"ou o "Basic English", que geraram um volume imenso de monografias para a descrição dessas línguas. Os estudiosos se beneficiam até hoje dessas pesquisas de fôlego, assim como das pesquisas estruturalistas, tão criticadas mas sempre tão citadas e tão necessárias a quem quer que se dedique ao estudo dessas línguas. Para o português, já temos dois grandes corpora de dados recolhidos, um no Brasil, para a língua culta, o NURC - Norma Urbana Culta (que tem seu correlato nos países de fala espanhola ${ }^{6}$ ) e outro em Portugal, publicado só recentemente (início dos anos 90), o Português Fundamental, correlato dos grandes projetos acima mencionados. No entanto, a quantidade de estudos que explorem o grande volume de dados desses doiscorpora ainda está muito aquém do desejado e do necessário.

Porém, como a demanda de profissionais treinados no ensino de português como segunda língua não pode esperar pela consecução da atividade de pesquisa, isto é, não se pode esperar a formação prévia de massa crítica para depois se instituir uma licenciatura, deve-se encontrar solução paliativa.

Uma alternativa de emergência seria a criação de cursos de pósgraduação a nível de especialização, que têm a vantagem de poderem propiciar embasamento e treinamento mais específicos num prazo relativamente curto em relação à implantação de licenciatura. O processo para se criar uma licenciatura é em si mais demorado e bastante burocratizado. A própria licenciatura demanda em média quatro anos para sua integralização. Além disso, um curso de especialização, tendo como clientela formados em Letras, poderia funcionar como complementação nos domínios específicos de ensino de segunda língua. Os ensinamentos incluiriam Análise Constrativa, Fonética / Fonologia, Psicolingüistica, Sociolingüística, Cultura Brasileira, Redação Específica (comercial, oficial, protocolar, etc.), Didática e Conversação entre outros, voltados especialmente para os problemas característicos do ensino de língua estrangeira.

6 BENTIVOGLIO $(1987$, p.21) assinala e lamenta a ausência de exploração dos dados do projeto da Norma Culta para elaboraçāo de descriçōes do espanhol Venezuelano. 
A natureza dos cursos de especialização poderia inclusive atender a uma demanda de profissionais de outros países, já detentores de uma licenciatura, visto que é possível, por meio de convênios, realizá-los fora das sedes das universidades.

A vantagem, pelo menos emergencialmente, dos cursos de especialização sobre as licenciaturas é a de nāo criar expectativas de mercado, inerentes às licenciaturas, pois eles só vão acrescentar uma espècialidade a alguém já habilitado. Evitariam, por conseguinte, um certo modismo e exploração comercial na criação aleatória de cursos, mal equipados e com profissionais mal ou pouco preparados, no caso de aprovar-se a criação de habilitação específica em português como segunda língua.

Acreditamos, por isso, que a discussão sobre a validade ou não de se instituir licenciatura em portugues - segunda língua vai depender exclusivamente do sucesso da empreitada do MERCOSUL e da fixação de um mercado de trabalho que justifique a criação de uma opção a mais nos cursos de Letras.

\section{RESUMO}

Com a criação do MERCosLL, originou-se a perspectiva de um mercado de trabalho para o ensino de português como língua estrangeira. Porém, não havendo ainda uma tradição firmada nessa área, defronta-se com o problema de como formar, a curto prazo, docentes habilitados para atender a essa demanda, tanto no Brasil como nos outros países integrantes do MERCOSLL. trangeira.

Palavras-Chave: Formação de docentes, MERCosul, Portuguès Língua Es-

\section{RÉSUMÉ}

La création du MERCOSUL a fait apparaitre la perspective d'un nouveau marché de travail, celui concernant l'enseignement de portugais comme langue seconde. Mais, comme il n'y existe pas encore une tradition dans ce champ, il se pose donc le problème de la formation de professionnels, dans un délai très réduit, préparés pour faire face à cette demande, aussi bien au Brésil quaux autres pays de ce marché commun. 


\section{REFERÊNCIAS BIBLIOGRÁFICAS}

ALMEIDA FILHO, J.C; LOMBELLO, L.C. (orgs.) O ensino de português para estrangeiros: pressupostos para o planejanento de cursos e elaboração de materiais. Campinas : Pontes, 1989.

BENTIVOGLIO, Paola. "A variação nos estudos sintáticos". Estudos Lingüisticos, Campinas, XIV : 07-29. (Anais de Seminários do GEL), 1987.

BENVENISTE, Claire-Blanche. EUROM 4: projet européen d'enseignement simultané de trois langues romanes. Conferência proferida no Colloque de Linguistique des Langues Romanes, Université de Sorbonne, Paris, 25-06-93, 1993.

COSERIU, Eugenio. "Sistema, norma e fala". In: Teoria da linguagem $e$ lingü̈stica geral: cinco estudos. [Trad. bras. por A. D. Carneiro], São Paulo : EDUSP / Rio : Presença. p. 13-85, 1979.

SECRETARIA DE ESTADO DA EDUCAÇÃO DO PARANÁ. Anais do Seminário Educação Sem Fronteiras [Foz do Iguaçu, 17 a 19 de novembro de 1993], Curitiba : SEED, 1993. 